\title{
Crença e ilusão: a crítica freudiana da religião
}

Fábio Moreira Vargas

\section{Resumo}

O artigo tem o objetivo de apresentar alguns aspectos da crítica freudiana à religião. Acompanhando, neste tema, as principais ideias do fundador da psicanálise, procura-se mostrar a articulação entre algumas estruturas do funcionamento do inconsciente e o fazer religioso, trabalhando a analogia feita por Freud entre a crença religiosa e a ilusão. O tema é longo e de difícil abordagem. Não há condição aqui de aprofundar as principais questões. Resume-se a um pequeno percurso pela interpretação do fato religioso elaborada pela obra de Freud.

Palavras-chave: Psicanálise - Religião - Crença e Ilusão. 


\title{
I. Introdução
}

\begin{abstract}
Às vezes temos a impressão, ao saber de atos cruéis acontecidos na história, de que os motivos ideais só teriam servido como pretextos para os apites destrutivos; outras vezes, no caso das atrocidades da Santa Inquisição, por exemplo, achamos que os motivos ideais se impuseram à consciência enquanto os destrutivos lhes trouxeram um reforço inconsciente
\end{abstract} Freud, Por que a guerra?

Desde que a crítica freudiana adentrou as áreas sagradas da sociedade, parece-nos que os ideais mais elevados e insistentemente buscados pela civilização tornaram-se efeitos de causas muito menos nobres do que se queria supor. A crítica freudiana à religião, diretamente, parece ser um dos pontos mais altos em que a descoberta das estruturas inconscientes faz eco. Se crer, orar etc. eram atividades de fundamento transcendente e teriam como fim uma experiência sobrenatural (diálogo entre Homem e Deus, bem como a mediação direta deste para aquele), depois da incursão do discurso psicanalítico nos atos ditos religiosos, essas atividades tornar-se-ão, no mínimo, extravagantes. O homem é um animal de ilusões, a psicanálise nos mostrou, tendo no seu âmago um vazio, uma carência que merece um estatuto de constituinte da própria condição humana. Nossas buscas e inquietações, bem como a forma como o homem se relaciona com os outros, têm, nesse vazio, motivação essencial. Ilusões e fantasias sempre prontas a renascer para que esse insaciável vazio seja preenchido devem ser levadas em consideração para a construção dos mais "elevados" edifícios da cultura humana. Ter-se feito o melhor pai, produzido o inesquecível gozo, ter no filho a criança essencialmente inocente, súmulas das fantasias clássicas dos homens, bem como ter na experiência religiosa a salvação de um mundo cruel, de destruição e de desejos dos mais perversos, faz Freud enfaticamente nos dizer que a religião é a neurose coletiva dos homens.

Frustração, desejo e destrutividade são chaves para a interpretação psicanalítica da religião. De forma menos profunda do que o tema pediria, façamos uma pequena incursão pelo i) modelo onírico como base da interpretação do fazer religioso, chegando a ii) aproximação dos processos patologia e religião para, enfim, a iii) figuração de deus com base na exportação da relação com o pai. Procuramos assim, na medida do possível, estabelecer a relação de crença como ilusão no pensamento freudiano. 


\section{O modelo onírico}

O modelo colocado por Freud de como se dá a atuação psíquica inconsciente é chave para entender as manifestações da vida consciente (patológicas e sadias). De fato, os sonhos são a porta de acesso a este modo peculiar de funcionamento. Partindo da interpretação onírica de como os mecanismos inconscientes atuariam, Freud pôde, munido do conhecimento desse funcionamento, abordar a grande produção da cultura humana. A concepção de que pela forma de como atuariam as estruturas inconscientes teríamos a chave para interpretar (compreender) as manifestações mitológicas, bem como as motivações filosóficas e, evidentemente, a religião, acompanhou Freud por toda sua vida teórica.

Não cabe aqui aprofundar a questão de como se dá o sentido do sonhor, basta para nós a fórmula basilar da análise dos sonhos: "o sonho é a realização de um desejo".

O desejo surge na teoria psicanalítica como propulsor da atividade humana, e, manifestado nas mais variantes formas, é especificamente na maneira como ele se manifesta no sonho que poderá nos servir de base para compreendermos como ele também se coloca nas outras esferas da vida. Sonhar, diz Freud, é realizar um desejo alucinatoriamente, mas de que forma? Um desejo inconsciente não podendo manifestar-se de forma desperta (isto é, na vida cotidiana consciente) se utiliza do estado de relaxamento da vida onírica para ter voz. Contudo, a face de tal desejo, mesmo com a vida subjetiva em estado onírico, não pode se fazer presente de forma óbvia. A psicanálise nos revelou haver conflitos internos no próprio sujeito em distintas instâncias psíquicas a todo o momento. Dessa forma, desejos que pertencem ao sistema inconsciente estão lá por não poderem ter acesso à consciência. E esta, numa tarefa de proteger-se contra tais desejos insuportáveis para a vida consciente, bloqueia constantemente a entrada de tais desejos. É nesse sentido que Freud nos lançará o modo privilegiado de como tais desejos conseguem adentrar a vida consciente do sujeito. Pelos mecanismos deslocamento e condensação temos a "máscara" utilizada pelos desejos para adentrarem a vida consciente. O deslocamento seria a mudança de foco de um desejo para outro por via associativa. Desejos que habitassem o sistema inconsciente poderiam, por via de associação, transferir sua carga representacional para um compo-

I A este respeito, para uma boa base teórica inicial, ver GARCIA-ROZA. Introdução à metapsicologia freudiana, vol. II. São Paulo: Editora Jorge Zahar, I996. 
nente (nesse caso, no sonho, uma imagem) da vida consciente. No lugar de revelar desejos agressivos contra pessoas "protegidas pelas concepções sociais" como membros íntimos da família, no sonho, a agressividade é posta contra alguém que não conhecemos. Porém, na interpretação, dirá Freud, há elementos deslocados de tal membro social para esta figuração da personagem "estranha" no sonho. Por exemplo, olhos marcantemente azuis que se deslocam de um membro para a personagem. É por via de deslocamento que o inconsciente manifesta-se, pelas suas representações deslocadas, na vida psíquica consciente. Por condensação entendem-se vários elementos inconscientes colocados em um único representante consciente o que faz a interpretação pelo sentido oculto do sonho ser praticamente interminável ${ }^{2}$. Temos, para nosso estudo já o necessário: Freud nos dirá que este modo de operar nos sonhos será a forma essencial de como o inconsciente se manifesta em toda a vida psíquica. Não somente nos sonhos, mas na vida desperta (como atos falhos, chistes e processos de formação de sintomas) e nos edifícios da cultura como a mitologia e a filosofia, por exemplo os desejos inconscientes encontram sua expressão de forma deformada. É nesse sentido que o modelo da interpretação dos sonhos nos dará a construção essencial para penetrar nas manifestações da vida cultural dos homens, por nos auxiliar na busca pela interpretação oculta de seu significado. Ora, o registro da legítima manifestação religiosa, após Freud, converte-se num delirante acesso aos desejos ocultos. Os pressupostos religiosos não mais dizem a uma realidade óbvia de transcendência, mas antes, a uma expressão deformada de desejos inconscientes. Estamos já na aproximação entre crença e ilusão.

\title{
III. Da patologia à religião: neurose e psicose
}

\author{
Qual é, pois, o significado psicológico das ideias religiosas? \\ Como podemos classificá-las? Não é fácil, de modo algum, responder a essa questão \\ imediatamente. Depois de rejeitar diversas formulações, nos deteremos nesta: \\ as ideias religiosas são proposições, são enunciados acerca de fatos e circunstâncias da \\ realidade externa (ou interna) que comunicam algo que o indivíduo não encontrou por conta
}

\footnotetext{
2 Não se esgotam aqui os mecanismos de funcionamento do inconsciente propostos por Freud. Além dos já citados, podemos encontrar a "condição à figurabilidade", "a elaboração secundária", bem como a "regressão" e a "sobredeterminação". Esta última, um dos núcleos do debate hermenêutico pós-freudiano. A este respeito, para um aprofundamento ver GARGIA-ROZA. Freud e o Inconsciente. Rio de Janeiro: Editora Jorge Zahar, 2013.
} 
própria, e que reivindicam que se creia nelas. Visto que informam sobre aquilo que mais nos importa e mais nos interessa na vida, elas gozam de alta consideração. Quem delas nada sabé é deveras ignorante; quem as incorporou aos seus conhecimentos pode se considerar enriquecido Freud, O futuro de uma ilusão.

No projeto do funcionamento psíquico proposto por Freud, um querer inconsciente proveniente do recalcado ${ }^{3}$ se manifesta como imposição constante ao querer e agir consciente do sujeito. A religião seria evidentemente um posicionamento às exigências da vida consciente. Como proibição da sexualidade, para dar apenas um exemplo, a religiosidade se colocaria como forte aliada contra as manifestações do desejo inconsciente; assim, também promotora das mais diversas neuroses que, como Freud exaustivamente nos mostrou, a causalidade (etiologia) das neuroses reside fundamentalmente no recalcamento de desejos.

A analogia entre os processos de neurose (patologia de um modo geral) e religião foi ganhando corpo cada vez mais amplamente na obra freudiana. Dos rituais obsessivos do neurótico às práticas religiosas, a semelhança é explícita. Ambos orientam-se por sentimentos inconscientes recalcados: da sexualidade sem expressão ao sentimento de culpa, religiosos e neuróticos se veem reféns de suas práticas. No ato religioso, contudo, a patologia fica longe de ser concebida, afinal sendo o edifício da religião um momento alto da cultura e da civilização, não caberia dar-lhe o estatuto de manifestação neurótica em seus comportamentos e crenças. Tirar o véu do sagrado como atividade de transcendência e afirmação de uma realidade ativa para fora do sujeito, para torná-la consequência de desejos ocultos que se manifestam por vias associativas, como já vimos, deslocadas, é a crítica freudiana da religião.

Não se trata simplesmente de negar a realidade divina, bem como colocar em questão ideias tradicionais como destino, oração e supressão da sexualidade, mas, antes, a investigação interna dos reais motivos que levam os homens a dedicar a vida às crenças infundadas e, sob a ótica psicanalítica, neuróticas.

3 Tema de extrema complexidade e abordagem ampla dentro dos comentários à obra de Freud, aqui, em linhas superficiais, compreende-se recalcamento como o processo de banir da consciência representações que não estejam de acordo com a vida consciente. A moralidade, insistida a nível psíquico pela instância Super-Eu, pressiona o processo de recalcamento, em que uma representação, manifestação de um desejo, poderá ser banida do sistema consciente e encontrará lugar de permanência ativa no inconsciente. 
A analogia dos processos está estabelecida. O neurótico sofre com seus recalcamentos, já que o desejo inconsciente é capaz de se manifestar de formas deslocadas. O religioso, por sua vez, não vendo na sua conduta obsessiva e deformada expressões de seus desejos mais proibidos, tem na religião (que por sua vez é coletiva) a manifestação do mais sublime e edificante fato espiritual. Parafraseando Morano (20I4): "basta que se retire o louco que anda gesticulando pelas ruas e coloque-o dentro de um templo para que o processo de loucura se converta em devoção e manifestação originária do contato com deus" (MORANO, 2OI4, p. IIO).

Estabelecida a analogia, que coloca outra chave interpretativa para se pensar a própria noção de patologia e normalidade, abordemos mais um aspecto interessante antes de concluírmos esta parte. É dada à psicose a característica de negar a realidade exterior. Convertendo o mundo percebido no mais completo jogo de ilusões, o psicótico situa-se muito mais no mundo interior, projetando para fora suas problemáticas que surgirão como realidade fora de si, do que no exterior. Ora, uma definição razoável colocaria o louco como aquele que afirmaria realidades não empíricas, não comprovadas e, preso nas próprias ilusões que o perseguem, não se dá conta da interioridade (conflituosa, claro) que engendraria "modificações" da realidade externa. Cria, dessa forma, outro mundo onde reside de forma certamente ambivalente, pois, tendo, nesse caso, uma patologia explícita, não teria condição de distinguir a polaridade dentro/fora, mundo/eu, subjetividade/objetividade.

Por essa rápida exposição, a crença religiosa, na medida em que projeta desejos ao mundo exterior e cria ilusões contrárias à realidade, transforma-se, pela ótica freudiana, numa demência de caráter alucinatório. Vistas coletivamente, as concepções religiosas em suas crenças ilusórias e motivadas, como já insistido, pelo mundo interior do sujeito são levantadas como manifestação de uma maioria que teria acesso assim a uma verdade transcendente. De fato, a chave para a interpretação dessa manifestação coletiva reside na infância da história subjetiva. Partindo de processos muito similares, teriam os homens na religião a manifestação coletiva naquilo que foram (e são) desejos primitivamente infantis. Abordando que seriam esses desejos e suas articulações com a figura de deus, caminhamos para o final desse percurso.

\section{Iv. A figura Deus}

Cabe-nos agora dado nosso pequeno percurso, investigarmos a condição infantil do homem - donde Freud se inspirará para toda a análise psicanalítica 
da vida adulta - e vermos a articulação desse período da vida humana com as manifestações culturais da vida adulta. No que se refere às características da religião, Freud é explícito:

[...] aquilo que o homem comum entende como sua religião, o sistema de doutrinas e promessas que de um lado lhe esclarece os enigmas deste mundo com invejável perfeição, e de outro lhe garante que uma solícita Providência velará por sua vida e compensará numa outra existência as eventuais frustrações desta (FREUD, 20I3c, p. 27).

Delírio e religião já estão, na articulação freudiana, juntas. As compensações de uma vida injusta e cruel e as providências que nos tirarão da lamúria de um destino implacável recebem por parte das promessas religiosas um belo lenitivo. O sistema religioso em Freud aparece como súmula de irracionalidades que confortam a vida do humano. Livrar-se completamente de tais promessas é um projeto no qual o próprio Freud se vê cético, justamente pela força dos desejos dos quais as religiões seriam consequência. Mas desvendar as causas de tal posição de extrema submissão já é uma contribuição que a psicanálise nos legou. Freud prossegue,

essa Providência o homem comum só pode imaginar como um pai grandiosamente elevado. Apenas um ser assim é capaz de conhecer as necessidades da criatura humana, de ceder a seus rogos e ser apaziguado por seus arrependimentos. Tudo isso é tão claramente infantil, tão alheio à realidade, que para alguém de atitude humanitária é doloroso pensar que a grande maioria dos mortais nunca se porá acima desta concepção de vida. Ainda mais vergonhoso é constatar que um bom número de contemporâneos, embora percebendo como insustentável essa religião, procuram defendê-la palmo a palmo, numa lamentável retirada (FREUD, 20I3c, p. 27).

A chave para resolução fora dada. A infantilidade dos eventos religiosos revela justamente a condição anterior a que temos de nos remeter para a análise. A infância humana está repleta de ilusões que são parte essencial do nosso amadurecimento. Griaturas completamente dependentes da ajuda parental, os seres humanos deparam-se com um mundo de frustração inevitável. O processo de adentrar gradativamente a vida adulta coloca-nos diante da suprema realidade que oprime os desejos mais essenciais. Da completa visão infantil de tudo querer e de tudo conseguir (onipotência dos pensamentos) para uma realidade que nos obriga a ceder em nossas 
próprias vontades, os seres humanos assistem à transformação daquilo que em Freud seria a mudança de foco do princípio do prazer para o princípio de realidade 4 . A presença materna não é alcançada a todo momento, as vontades curvar-se-ão diante a uma moral vigente que determina o fazer e como fazer. A anterior busca por prazer que não leva em consideração as limitações da realidade dá lugar a um mundo onde o narcisismo ${ }^{5}$ infantil deve ser drasticamente apaziguado. Crescer se converte num tornar-se sociável mediante regras e imposições que contrariam as vontades individuais. Glaro fica que a maneira como cada indivíduo entende a realidade exterior e a forma como se articulam frustração e desejo serão movimentos indispensáveis para se pensar o próprio desenvolvimento futuro do homem. A religião surge assim como incentivadora da manutenção de uma realidade que não se aproxima da racional para o sujeito. Dando uma resposta fundamental para uma das maiores questões da filosofia e um dos maiores temores humanos a religião garante-nos que seremos recompensados numa vida futura. A imortalidade surge como passo exemplar de um desejo humano projetado numa realidade exterior que se legitima pelo supremo poder da providência divina. "Acolhemos as ilusões porque nos poupam sentimentos desagradáveis, permitindo-nos em troca gozar satisfações. Portanto, não devemos reclamar se, repetidas vezes, essas ilusões entrarem em choque com alguma parcela da realidade e se despedaçarem contra ela" (FREUD, 20I3b, p. 218).

Tal providência divina e sua nítida associação com um desejo humano, a saber a imortalidade como citado anteriormente, leva-nos ao último ponto dessa brevíssima incursão: a figura de deus.

A ambivalência de sentimentos, assunto de grande profundidade na psicanálise, foi-nos revelada para o escárnio de uma sociedade que buscava pureza absoluta no mundo infantil. Ódio e amor coexistem para com as pessoas que nos cuidam. A família, pai e mãe (enquanto funções, claro), desperta por

\footnotetext{
4 Modo operante do funcionamento psíquico, o princípio de prazer seria a forma como o inconsciente buscaria sua satisfação sem levar em conta a realidade para tal. Com o tempo, em contato com a realidade externa por meio dos órgãos dos sentidos, outro princípio instaura-se para fazer frente à busca absoluta de prazer, trata-se do princípio de realidade. Assunto de extrema importância na metapsicologia freudiana, aqui citamos apenas a título de elucidação.

5 Concepção de relevância no edifício teórico da psicanálise, as formulações sobre narcisismo adquirem importância crucial a partir de I9I4, ano de mudança da teorização psicanalítica. Por Narcisismo entende-se o momento em que todas as intenções pulsionais encontram-se voltadas para o próprio sujeito. O interesse pelo mundo bem como as outras fases, como a objetal, que sucederá a fase narcísica ainda não teve expressão.
} 
parte da criança desejos amigáveis e amorosos bem como destrutivos e egoístas. Parte recalcada, o ódio e os sentimentos ditos ruins são banidos da consciência e encontrar-se-ão vivos no inconsciente. Já sabemos, eles retornam como manifestações disfarçadas para a vida consciente. Ora, a aproximação entre a figura paterna e deus é colocada de forma explícita por Freud. Pai amado porque protege, odiado porque castra, idolatrado porque nos é ideal, temido porque opressor. A dinâmica ambivalente dos sentimentos é a última chave para perceber que tais desejos contra a ordem paterna retornam juntamente com os desejos a seu favor. Ódio e amor se encontram nas manifestações deslocadas da religião. Para a providência divina cabe a proteção e amor incondicional. A projeção de um Deus glorioso e imortal. Para a face odiada, temida e responsável pelas frustrações e privações da vida, a face paterna adquire o nome de satanás. ${ }^{6}$ Projeções dos mesmos desejos, deus se apresenta como modelo da forma como opera o inconsciente.

A religião certamente não detém o monopólio das construções ilusórias baseadas nos desejos humanos. Contudo, é dela o maior peso na tarefa de manter as crenças ativas. Como bem nos coloca Morano: "O segredo de sua força [religião], como no sonho, reside exclusivamente na força do desejo da qual derivam” (MORANO, 2OI4, p. 6I).

$\mathrm{Na}$ sua finita existência, o humano se depara com fortes sentimentos de desamparo e completa desproteção. Regride-se, desse modo, àquela familiar situação infantil em que se foi amparado e devidamente protegido pelas figuras da paternidade. Recriando a sensação de conforto, o motor para produção da divindade como o "grande pai" é dado.

Imortalidade, recompensa de uma vida de catástrofes, punição para nossos inimigos, sorte e boa ventura, felicidade garantida pelas ações que devem ser cumpridas, pai que ama igualmente a seus filhos pronto a satisfazer suas necessidades, apto ao perdão, bem como a oração que nos leva a comunicação direta com ele figuram-se, desse modo, em ilusões irracionais de um infantilismo que nos impede de lidar com a realidade opressora. Orar torna-se um diálogo cego, em que se mira o transcendente e atinge-se o próprio sujeito preso em seus desejos mais temidos e ocultos. A caracterização da crença (todo ato religioso em essência) como quadro ilusório é exatamente por produzir

6 A questão da maternidade também é assunto de ampla importância para análise crítica de Freud. Embora bem menos trabalhada, é possível encontrar referências do sentimento oceânico que engendraria as religiões com o estado infantil quase simbiótico entre o sujeito e sua mãe. Aqui, cabe-nos a figuração paterna para nossa análise. 
uma realidade completamente avessa erguida sobre os próprios desejos dos quais não encaramos de forma consciente.

A aproximação entre sintoma e religião se manifesta na exata medida em que, ambos, ao olhar psicanalítico, devem ser interpretados em busca do seu sentido outro (inconsciente). O temor da finitude da vida nos coloca diante da imortalidade da alma humana e mais, na projeção de um supremo pai (infantil) que nos garante a vida merecida pós-morte.

Quanto à irracionalidade, Freud nos diz que o inconsciente não conhece contradições. Tudo aquilo que se apresenta como discurso da razão, em referência a aproximação que temos da realidade, quando movidos por desejos de outra ordem, ganham expressão contrariando justamente aquilo que de mais imediato e sensato teríamos: a realidade tal como é. Dessa forma, numa espécie de alucinação que remedia as tragédias do destino, Freud pode tornar a análise da religião uma sintomatologia.

\section{v. Concluindo...}

As críticas freudianas da religião levantaram muitas páginas de prós e contras, como se era de esperar. O fato é que, depois da psicanálise, crer, orar e persuadir-se quanto a outro mundo é uma tarefa muito mais difícil. Se entregar-se às ilusões não é um caminho favorável à própria vida, ignorar a complexa estrutura de desejos e subjetividades também não parece ser uma boa opção. A finitude da vida, já em Freud, revela-se como peça de fundamental importância para a própria preciosidade dela. Na raridade da vida, finita e frustrada, talvez possamos, sem ignorar as causas de nossos comportamentos e neuroses, encontrar uma forma de viver longe das ilusões. Já que não nos cabe mais a onipotência outrora atribuída a nós mesmos, que se possa, na finitude do poder e do saber, desfrutar da vida da melhor forma possível. Os motivos que eram evidentes para justificar a crença podem e devem, depois do olhar interpretativo do psicanalista, procurar sua forma e legitimidade muito mais fundo do que supunha uma experiência imediata entre homem e deus.

\section{Referências bibliográficas}

FREUD, Sigmund. A interpretação dos sonhos. Rio de Janeiro: Editora Imago, I972. . Atransitoriedade. São Paulo: Editora Companhia das Letras, 20I3a. 
- Considerações atuais sobre a guerra e a morte. São Paulo: Editora Companhia das Letras, 20I3b.

. Por que a guerra. São Paulo: Editora Companhia das Letras, 20I3c.

- O futuro de uma ilusão. São Paulo: Editora Companhia das Letras, 20I3d. . O mal estar na civilização. São Paulo: Editora Companhia das Letras, 20I3e.

GARGIA-ROZA, Luis Alfredo. Freud e o inconsciente. Rio de Janeiro: Editora Jorge Zahar, 20I3. . Introdução à metapsicologia freudiana, vol. II e III. Rio de Janeiro: Editora Jorge Zahar, I996.

MORANO, Garlos Domínguez. Crer depois de Freud. São Paulo: Editora Loyola, 2014.

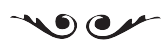

Fábio Moreira Vargas - Graduando em Filosofia pela Universidade de São Paulo.

fabio.vargas@usp.br 